\title{
O PROFESSOR MEDIADOR E AS TECNOLOGIAS DA INFORMAÇÃO E COMUNICAÇÃO NO ENSINO FUNDAMENTAL I
}

\author{
CURITIBA/PR MAIO/2018 \\ Jonas Rafael Nikolay - Uninter - jonas.nikolay@gmail.com \\ Ademir Aparecido Pinhelli Mendes - Uninter - ademir.m@uninter.com \\ Irene Zangalli - Uninter - irenezangalli@gmail.com \\ Tipo: Relato de Experiência Inovadora (EI) \\ Categoria: Métodos e Tecnologias \\ Setor Educacional: EDUCAÇÃO INFANTIL E FUNDAMENTAL
}

\begin{abstract}
RESUMO
Este trabalho tem o propósito de mostrar, por meio de relato de experiência fundamentado nos dados do Índice de Desenvolvimento da Educação Básica (IDEB), que a prática pedagógica do professor mediador, no processo da aquisição do conhecimento pelos estudantes com o uso das novas ferramentas de Tecnologias da Informação e Comunicação (TIC), é bastante eficaz na formação integral do indivíduo, sob os aspectos cognitivo, social e emocional. Como metodologia, optou-se pela perspectiva sociocultural de Vygotsky (1988), ao considerar o estudante como protagonista de seu conhecimento, com práticas alternativas às tradicionais, favoráveis a uma forma de aprender mais dinâmica, contextualizada e construtiva. Organizou-se um leque de sugestões ancoradas na experiência vivida ao longo de alguns anos de trabalho, baseando-se em uma postura de mediação do professor que permita ao estudante, considerado hoje nativo digital, usufruir das TIC para interagir, criar, errar, questionar e inovar.
\end{abstract}

Palavras-chave: Mediação. Professor. Tecnologias da Informação e Comunicação. 


\section{INTRODUÇÃO}

O estudo em questão busca, por meio de um relato de experiência, discutir o papel do professor frente ao uso das Tecnologias de Informação e Comunicação (TIC). Estas ferramentas interativas estabelecem possibilidades de aprendizado, com mediação pedagógica do professor, conforme pensado por Vygotsky (1988), que defendeu em sua teoria sociocultural a ideia de que a aprendizagem deve ocorrer em processos de relações sociais, com a colaboração de pessoas com mais experiência (LINS, 2003).

Este é, portanto, um relato de experiência das atividades realizadas no decorrer dos anos letivos de 2011 a 2016, período em que algumas professoras utilizaram vídeos, lego, tablet, netbook, filmadora e diversos aplicativos visando a elevação do aprendizado, do interesse e da autoestima dos estudantes de três turmas do Ensino Fundamental I de uma escola municipal situada na periferia da cidade de Curitiba-PR.

\section{MEDIAÇÃO DOCENTE}

Diante das mudanças na sociedade, impactando diretamente a escola e, de um ponto de vista mais amplo, todos os segmentos da sociedade, a utilização da tecnologia significa uma grande contribuição neste processo. A ampliação do acesso à internet, o avanço na utilização dos dispositivos móveis e o acesso à informação em tempo real afetam diretamente a escola em suas práticas, sua cultura e seus valores, inclusive a forma de relacionamento entre professor e aluno.

O objetivo fundamental das escolas tem sido historicamente a produção do conhecimento, dentro de princípios, práticas, cultura e valores que as norteiam. Mesmo com o passar dos anos e com as mudanças que impactam a sociedade, a expectativa que se tem sobre a escola continua a mesma. Moran (2013, pág. 93) comenta sobre o papel da escola nos dias atuais: "A produção do conhecimento com autonomia, com criatividade, com criticidade e espírito investigativo provoca a interpretação do conhecimento e não apenas sua aceitação". Para que o processo de produção do conhecimento aconteça, deve haver sintonia entre professor e alunos, e as mudanças na mediação da aprendizagem devem acompanhar e atender às demandas sociais.

A palavra mediação é utilizada para diversos ramos de atividades profissionais e acadêmicas, como, por exemplo, no terapêutico, no educacional e no jurídico. O objetivo neste trabalho é analisar a mediação no contexto educacional, com o propósito de 
representar a ação do professor no processo de desenvolvimento da aprendizagem de seus alunos. O professor que atua como mediador da aprendizagem tem um papel fundamental no desenvolvimento da autonomia do seu aluno despertando-lhe o interesse e a curiosidade pela busca da resolução das mais variadas questões. Uma definição que expressa bem o significado da mediação é a de Meier e Garcia (2011, p. 72):

Mediar significa, portanto, possibilitar, potencializar a construção do conhecimento mediado. Significa estar consciente de que não se transmite o conhecimento. É estar intencionalmente entre o objeto de conhecimento e o aluno de forma a modificar, alterar, organizar, enfatizar e transformar os estímulos provenientes deste objeto a fim de que 0 mediado construa sua própria aprendizagem, que o mediado aprenda por si só.

De acordo com Friedrich (2012, p. 110), Vygotsky desenvolveu o conceito de "Zona de desenvolvimento proximal", que antecipa os desenvolvimentos possíveis, o que a criança conseguirá fazer se acompanhada pelos adultos na resolução de tarefas e problemas. É esse movimento entre "o que ela sabe fazer" em direção "ao que ela poderia conseguir fazer" que os ensinamentos escolares deveriam focalizar. Assim, o professor tem um papel importante na mediação com os alunos, pois é por ela que o aluno pode aprender mais do que aprenderia se não contasse com o professor mediador, e o relacionamento entre eles tem extrema importância no desenvolvimento dos discentes.

O uso pedagógico dos recursos tecnológicos digitais, como computadores, celulares, internet e tablets na escola, como instrumentos de apoio na mediação da aprendizagem, é um assunto que necessita de análise sobre o processo em si e os reflexos desta utilização sobre os participantes, no caso o aluno e o professor, para constatar a eficácia da aprendizagem. Kenski (2013, p. 54) relata que:

[...] a mediação tecnológica facilita que novos projetos pedagógicos sejam criados, respeitando o ritmo de aprendizagem dos alunos - de todas as idades e níveis de ensino -, os espaços que eles se encontram e os tempos disponíveis para estudar e trabalhar.

Ao tratar do tema, não é possível desconsiderar a transformação no ambiente escolar, a modificação na organização das atividades curriculares que integram conteúdos e ações, para que respondam às necessidades do cotidiano. Moran (2013, p. 12) aprofunda essa temática ao enfatizar que "não são os recursos que definem a 
aprendizagem, são as pessoas, o projeto pedagógico, as interações, a gestão. Mas não há dúvida que o mundo digital afeta todos os setores, as formas de produzir, de vender, de comunicar-se e de aprender". Também Kenski (2012, p. 46) comenta o processo de mudanças: "Para que as TIC possam trazer alterações no processo educativo, no entanto, elas precisam ser compreendidas e incorporadas pedagogicamente, isso significa que é preciso respeitar as especificidades do ensino e da própria tecnologia para poder garantir que o seu uso realmente faça diferença."

Nos dias atuais, a aprendizagem e o desenvolvimento de habilidades se dão de forma diferente de como se davam em gerações passadas. Em todos os segmentos há a necessidade de sintonia com as crescentes exigências do mundo do trabalho e da sociedade em geral. Por isso, de acordo com Kenski (2012, p. 88), "é preciso que se organizem novas experiências pedagógicas em que as TIC possam ser usadas em processos cooperativos de aprendizagem, em que se valorizem o diálogo e a participação permanente de todos os envolvidos no processo". Esse pode ser o grande desafio que se apresenta para os professores, a necessidade de uma nova estruturação do seu tempo, para que possa acontecer a personalização da prática docente, visando atender às necessidades de cada um dos alunos de uma aprendizagem mediada, tendo os recursos tecnológicos como ferramentas.

No entanto, este processo ainda não acontece de maneira efetiva em grande parte das escolas. A reorganização do tempo do professor, da análise e restruturação das práticas pedagógicas, dos planos de ensino e organização da escola não acompanham as transformações que nela estão acontecendo. Pode-se observar a aquisição de equipamentos tecnológico de ponta, porém, mesmo contando com o recurso, o processo de mediação da aprendizagem acontece de maneira muito discreta, quando acontece. Em alguns casos, o recurso tecnológico não é utilizado por falta de conhecimento sobre a maneira adequada de fazê-lo. Kenski comenta: Alunos, professores e tecnologia interagindo com o mesmo objetivo geram um movimento revolucionário de descobertas e aprendizados. Essa formulação já mostra que a instrumentação técnica é uma parte muito pequena do aprendizado docente para a ação bem-sucedida da mediação entre educação e tecnologia. (KENSKI, 2012, p. 105).

A mediação da aprendizagem com a utilização das tecnologias disponíveis na escola deve direcionar a relação do professor com o aluno para não apenas ensinar e aprender, mas para a formação de um homem que reflita sobre seus atos e sua participação na sociedade, desenvolvendo-se de forma autônoma, consciente de sua responsabilidade para com o meio onde está inserido, sendo agente da própria transformação e ajudando a transformar a sociedade em que vive. 


\section{PROCEDIMENTOS METODOLÓGICOS}

O Instituto Nacional de Estudos e Pesquisas Educacionais Anísio Teixeira (Inep) implantou em 2007 o Índice de Desenvolvimento da Educação Básica (IDEB), com a finalidade de medir a qualidade da educação nacional e estabelecer metas para sua melhoria.

A equipe gestora e docentes de uma escola localizada em bairro periférico de CuritibaPR, após obter pelo IDEB um resultado decrescente em $2011(4,8)$ em relação ao ano de $2009(4,9)$, preocuparam-se em buscar alternativas de melhoria no ensino. Elegeram, por organização e decisão democrática, uma alternativa à forma tradicional. Esta organização se deu com o desejo de ofertar aos estudantes um ambiente alfabetizador, com dinâmicas e ferramentas tecnológicas diversas, a fim de oportunizar melhores condições de estudos.

Desde 2008 a escola passou a ofertar a modalidade de Educação em tempo Integral, e os estudantes passaram a permanecer na escola por nove horas diárias, visto que a maioria das crianças não possuem condições financeiras para frequentar outras entidades socioculturais, bem como para aquisição de livros e materiais que as auxiliem no desenvolvimento acadêmico. Para atender essa novidade, os trabalhos foram organizados por Salas Ambientes. Toda essa organização se deu em conformidade com as orientações da Secretaria Municipal de Ensino (SME) de Curitiba.

Numa postura de mediação do conhecimento, as professoras preocupavam-se em elaborar aulas mais dinâmicas e que despertassem interesse nos estudantes por meio do uso das TIC. De acordo com Freire (1996, p. 43-44),

Ensinar exige reflexão crítica sobre a prática: por isso é que, na formação permanente dos professores, o momento fundamental é o da reflexão crítica sobre a prática. É pensando criticamente a prática de hoje ou de ontem que se pode melhorar a próxima prática.

Cada professora assumiu a prática educativa com a qual tinha maior afinidade para trabalhar com estudantes de três turmas, numa dinâmica de rodízio. Ou seja, cada professora permanecia em sua Sala Ambiente e os estudantes, por sua vez, mudavam de salas, conforme cronograma pré-estabelecido. As atividades foram organizadas em dois períodos: num primeiro momento os estudantes, numa dinâmica parecida com a 
proposta de "Sala Invertida", realizavam as tarefas solicitadas pela professora do Ensino Regular, com a mediação da professora do Integral; e num segundo momento, participavam de atividades em grupos, utilizando-se das TIC.

Os artefatos tecnológicos eram diferentes, conforme o componente curricular que estava sendo trabalhado. Por exemplo, na Sala Ambiente de tecnologia os estudantes utilizaram ferramentas como tablet, lego, robótica, celular. Na Sala Ambiente de teatro os artefatos mais utilizados foram filmadoras, máquina fotográfica, celular, projetor, computador e os aplicativos spotify, de música e cymera. Na Sala Ambiente de educação ambiental, o microscópio, o "torso" humano didático, a horta e ferramentas afins. Utensílios de cozinha, computador, TV foram essenciais para a realização das atividades.

No momento que o docente organiza e planeja as tarefas em sala de aula, ele precisa buscar a aprendizagem inovadora para as aulas, despertando, dessa forma, o interesse do estudante. Com a utilização das TIC, o professor proporciona, pela prática educativa, que o estudante seja inserido na era digital e agregue conhecimentos de forma dinâmica e interativa. Para Behrens (2000, p. 72), "a tecnologia precisa ser contemplada na prática pedagógica do professor, de modo a instrumentalizá-lo a agir e interagir no mundo com critério, com ética e com visão transformadora".

\section{APRESENTAÇÃO E DISCUSSÃO DOS RESULTADOS}

Nos primeiros dias os estudantes apresentaram dificuldades em relação à pesquisa e às atividades em grupos. Tiveram a sensação de não saber por onde começar. Algumas desavenças e desentendimentos foram notados e houve necessidade de construir regras em conjunto. A partir de então os estudantes compreenderam a importância do trabalho por meio de pesquisa e resolução de problemas e a necessidade do outro. Passaram a se respeitar mais e a aceitar as diferenças de cada um. Para tudo isso, a mediação da professora tornou-se imprescindível.

Relatos das professoras que se envolveram com o trabalho corroboram a teoria sociocultural de Vygotsky, que tem como base a ideia de que a aprendizagem ocorre em processos de relações sociais, com a colaboração de pessoas com mais experiência, como também com seus pares. Assim, a postura de mediação e o uso das TIC resultaram na construção de um aprendizado mais eficiente, obtendo um crescimento significativo no IDEB, passando de 4,8 (2011) para 5,0 em 2013, e 5,2 em 2015. 
O professor mediador ajuda a criança a descobrir o que está a sua volta, ajudando desta forma a transformar o desenvolvimento potencial em desenvolvimento real. "Aquilo que é zona de desenvolvimento proximal hoje será o nível de desenvolvimento real do amanhã - ou seja, aquilo que uma criança pode fazer com assistência hoje, ela será capaz de fazer sozinha amanhã" (VYGOTSKY, 1988, p. 98).

O uso das TIC foi o ponto alto no crescimento do interesse dos estudantes em buscar o conhecimento. As ferramentas tecnológicas, quando bem aplicadas, exercem algo de mágico no mundo infantil. São perceptíveis a empolgação, o engajamento e a vontade de se superar e de resolver as situações-problema propostas pelo professor mediador, utilizando-se das TIC.

O professor, na sua prática pedagógica enfrenta um novo desafio, que é o de inserir as TIC no cotidiano escolar. O meio digital é uma realidade, e o docente dentro de suas possibilidades vai se adaptando a esta nova forma de ensinar. Observa-se que quando há utilização das TIC no processo de aprendizagem, os alunos tornam-se mais motivados para aprender e buscar novas interações que os ajudem na aprendizagem.

\section{CONSIDERAÇÕES FINAIS}

Espera-se que o professor que faz uso das TIC renove constantemente seu fazer pedagógico, sendo um profissional inovador e conectado nas novidades da era digital, elaborando aulas dinâmicas e que despertem grande interesse com uma metodologia atual. Assim, ele vai desenvolver os conteúdos propostos junto com os alunos, desempenhando o papel de mediador da aprendizagem, apresentando os objetivos de cada tema de aula por meio da mediação pedagógica e do uso das tecnologias. Behrens (2000, p. 77) mostra que em "um mundo globalizado, que derruba barreiras de tempo e espaço, o acesso à tecnologia exige atitude crítica e inovadora, possibilitando o relacionamento com a sociedade como um todo".

Muitas vezes espera-se que, ao colocar os recursos tecnológicos digitais à disposição no ambiente escolar, a transformação no processo de aprendizagem seja estabelecida, levando ao repensar do cotidiano escolar e à modificação na forma de mediar a aprendizagem, criando novas estruturas cognitivas, pois se amplia o espaço para debates e questionamentos junto a professores, alunos e sociedade. Estes questionamentos circundam a realidade do ensino-aprendizagem, já que os novos recursos podem modificar as relações entre o professor e o aluno. É visível o papel que as tecnologias digitais adquiriram neste século, e as probabilidades criadas por este fenômeno fomentam novas discussões sobre a sua utilização como ferramenta no 
processo da aprendizagem nas salas de aula.

\section{REFERÊNCIAS BIBLIOGRÁFICAS}

BEHRENS, M. A. Projetos de aprendizagem colaborativa num paradigma emergente. In: Novas tecnologias e mediação pedagógica . Campinas: Papirus, 2000.

DANIELS, H. (org.). Uma introdução a Vygotsky. São Paulo: Loyola, 2002.

FREIRE, P. Pedagogia da autonomia: saberes necessários à prática educativa. 7. ed. São Paulo: Paz e Terra, 1996.

FRIEDRICH, J. Lev Vigotski: mediação, aprendizagem e desenvolvimento: uma leitura filosófica e epistemológica. Campinas: Mercado das Letras, 2012.

KENSKI, V. M. Educação e tecnologias: o novo ritmo da informação. 8. ed. Campinas: Papirus, 2012. (Coleção Papirus Educação).

LINS, S. Transferindo conhecimento tácito: uma abordagem construtivista. Rio de Janeiro: E-papers, 2003.

MEIER, M.; GARCIA, S. Mediação da aprendizagem: contribuições de Feuerstein e de Vigotsky. 7. ed. Curitiba: Edição do Autor, 2007. 212 p.

MERCADO, L. P. L. (org.). Novas tecnologias na educação: reflexões sobre a prática. Maceió: EDUFAL, 2002.

MORAN, J. M. Ensino e aprendizagem inovadores com tecnologias audiovisuais e telemáticas. In: . Novas tecnologias e mediação pedagógica. Campinas: Papirus, 2000.

MORAN, J. M.; MASETTO, M. T.; BEHRENS, M. A.. Novas tecnologias e mediação pedagógica. 21. ed. Campinas: Papirus, 2013. (Coleção Papirus Educação).

SANTOS, B. S. dos. O processo de internalização. In: LA ROSA, J. de (org.). Psicologia e educação: o significado do aprender. 7. ed. Porto Alegre: EDIPUCRS, 2003, p. 134. 
VYGOTSKY, L. S. A formação social da mente: o desenvolvimento dos processos psicológicos superiores. São Paulo: Martins Fontes, 1988. 